\title{
Glacier Surface Velocity Measurements from Radar Interferometry and the Principle of
} Mass Conservation

\author{
Mohr, Johan Jacob; Reeh, Niels
}

Published in:

Proceedings of IEEE International Geoscience and Remote Sensing Symposium

Publication date:

2002

Document Version

Publisher's PDF, also known as Version of record

Link back to DTU Orbit

Citation (APA):

Mohr, J. J., \& Reeh, N. (2002). Glacier Surface Velocity Measurements from Radar Interferometry and the Principle of Mass Conservation. In Proceedings of IEEE International Geoscience and Remote Sensing Symposium (pp. 1054-1056). IEEE.

\section{General rights}

Copyright and moral rights for the publications made accessible in the public portal are retained by the authors and/or other copyright owners and it is a condition of accessing publications that users recognise and abide by the legal requirements associated with these rights.

- Users may download and print one copy of any publication from the public portal for the purpose of private study or research.

- You may not further distribute the material or use it for any profit-making activity or commercial gain

- You may freely distribute the URL identifying the publication in the public portal

If you believe that this document breaches copyright please contact us providing details, and we will remove access to the work immediately and investigate your claim. 


\title{
Glacier surface velocity measurements from radar interferometry and the principle of mass conservation
}

\author{
Johan Jacob Mohr ${ }^{1}$ and Niels Reeh ${ }^{2}$ \\ ${ }^{1} \emptyset$ rsted•DTU, Technical University of Denmark \\ Ørsteds Plads B-348, DK-2800 Kgs. Lyngby, Denmark \\ ${ }^{2}$ Arctic Technology Centre, Technical University of Denmark \\ Kemitorvet B-204, DK-2800 Kgs. Lyngby, Denmark
}

\begin{abstract}
This paper presents a relation between the three glacier surface velocity components, the surface flux-divergence, glacier thickness and bottom melt and displacement. The relation can be used as an extension to the surface parallel flow assumption often used with interferometric synthetic aperture measurements of glacier velocities. The assumptions for the derivation are described and important limitations high-lighted.
\end{abstract}

\section{INTRODUCTION}

Conventional interferometric synthetic aperture radar can provide measurements of surface displacement (velocities) in one look direction. By using data from ascending and descending orbits two independent velocity components can be measured. Combined with e.g. a surface parallel flow assumption the 3-D velocity field can be derived, [1], [2].

In [3] the surface parallel flow approach is extended with a submergence/emergence term derived using the principle of mass conservation. The method is applied to a glacier in the ablation zone in [4], and accuracy issues are discussed in [5].

The extension accounts for the submergence/emergence velocity which, particular in the ablation zone, is often many meters per year even for glaciers in steady state. The draw-back is that it requires knowledge of ice-thicknesses. Additionally, it requires assumptions on the flow inside the ice body and on the conditions at the glacier bottom. Such assumptions, though, are strictly speaking required with all methods for 3-D velocity extraction based on 1-D or 2-D surface velocity measurements.

The purpose of the present paper is to provide a presentation of the ideas in [3] and to highlight the underlying assumptions. The present paper additionally uses a more realistic assumption for the density-depth profile. This does not change the results in the ablation zone, but has some implications in the accumulation zone.

First we describe the surface boundary condition and the equation of continuity for a glacier. Combined they provide a relation between the horizontal and the vertical velocity components. Finally, we describe how the relation may be used in the ablation zone and highlight some fundamental limitations.

\section{SURFACE BOUNDARY CONDITION}

The surface boundary condition for an ice sheet,

$$
\frac{\partial S}{\partial t}=-\vec{v}_{S} \cdot \operatorname{grad} S+w_{S}+b_{S},
$$

is given in [3]. It relates rate of change of the surface elevation, $\partial S / \partial t$, to the horizontal velocity vector $\vec{v}_{S}$, the surface slope $\operatorname{grad} S$, the vertical ice-particle (pole) velocity, and the specific mass balance. The instantaneous specific mass balance, $b_{S}$ is measured in meters per time unit of the material which is added/removed by the accumulation/ablation process. Equation (1) is valid at any instant.

The first term on the right-side of (1) depends on the orientation of the coordinate system used. For example, in a coordinate system aligned with the surface, this component is zero. This term is denoted the surface parallel flow component. The term, $w_{S}$, is the vertical velocity of an ice particle. The sum of the first two terms, $w_{S}-\vec{v}_{S} \cdot \operatorname{grad} S$, is the submergence/emergence velocity, i.e. the upward or downward flow of ice relative to the surface at a point fixed in space. The last term describes the surface elevation change related to mass balance.

\section{EQUATION OF CONTINUITY}

The vertically integrated equation of continuity for an ice sheet,

$$
\frac{\partial m}{\partial t}=-\operatorname{div} \vec{q}+b_{S} \rho_{S}+b_{B} \rho_{B},
$$

is given in $[6$, p. 256]. It states that there are three terms which may change the mass, $m=\int_{B}^{S} \rho \mathrm{d} z$, of a column of unit area fixed in space. The first is the divergence of the two-dimensional mass flux vector, $\vec{q}$, with the components, $q_{x}=\int_{B}^{S} \rho u \mathrm{~d} z$, and $q_{y}=\int_{B}^{S} \rho v \mathrm{~d} z$, where $(u, v)$ are the horizontal velocity components. The last two terms state that mass may additionally be added from the surface, $S$, and the bottom, $B$. Again, the specific mass balances, $b_{S}$ and $b_{B}$, are measured in meters per unit time of material with the specific densities $\rho_{S}$ and $\rho_{B}$. Equation (2) is also valid at any instant.

The critical part in our analysis is to derive an equation which relates the surface change rate, $\partial S / \partial t$, to the column mass change rate, $\partial m / \partial t$. As an extension of [3, App. B] we here assume that

Assumption A: The density-depth profile is composed of two segments, see Fig. 1. The upper segment describes accumulating/melting snow or ice. The lower segment with a thickness $h_{1}$ describes the average (long term) density depth profile. The shape of its upper part is assumed timeinvariant. 


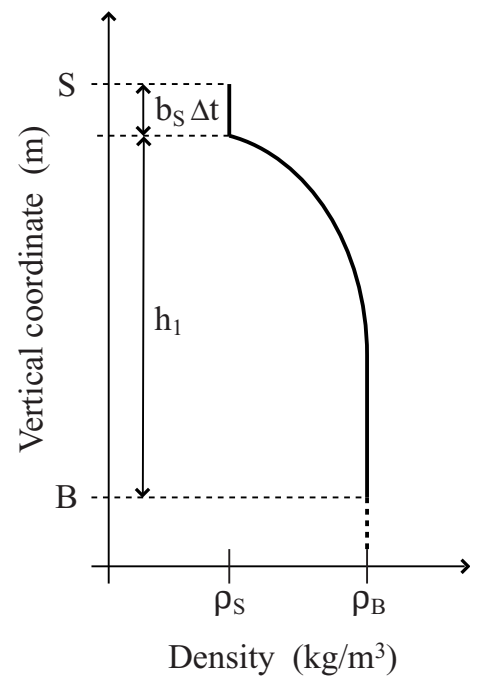

Fig. 1. Depth-density model. In the ablation zone, where $\rho_{S}=\rho_{B}$, it degenerates to a uniform distribution. Upper part accounts for the short term mass-balance. The shape of the lower part is assumed time-invariant.

In the following a number of processes which potentially change the depth-density profile over time at a fixed position are described. The changes are most pronounced in the accumulation zone and assumed very small in the ablation zone with ice from the surface to the bottom.

Climate related density variations are investigated in [7]. From [7, Fig. 3] we estimate a compression of the depthdensity profile on the order of $0.5 \mathrm{~cm} / \mathrm{y}$ for a $1 \mathrm{~K}$ change in surface temperature; with Byrd station surface conditions. From [7, Fig. 4] we estimate an extension of the depth-density profile on the order of $1.5 \mathrm{~cm} / \mathrm{y}$ for a $10 \%$ change in accumulation.

Seasonal and shorter variations of temperature and accumulation are assumed to cause larger variations of the densitydepth profile, but we do not have any estimates. However, in terms of combination with interferometric measurements, the problem is reduced, since the radar penetrates up to some tens of meters into firn.

Also, the depth-density profile is likely to change in case of a non-stationary flow, but again we do not have estimates for the significance of this effect.

Using assumption $\mathrm{A}$, the mass-change rate can be calculated as

$$
\frac{\partial m}{\partial t}=\rho_{B} \frac{\partial h_{1}}{\partial t}+\rho_{S} b_{S} .
$$

We also have that ice-thickness $S-B$ may be calculated as

$$
S-B=h_{1}+\int b_{S} \mathrm{~d} t .
$$

An expression for the mass change rate in a unit column can now be derived by inserting the derivative of (4) in (3), which yields

$$
\frac{\partial m}{\partial t}=\rho_{B}\left(\frac{\partial S}{\partial t}-\frac{\partial B}{\partial t}\right)-b_{S}\left(\rho_{B}-\rho_{S}\right) .
$$

Under the assumption A), the equation of continuity, valid at any instant, may finally be written as

$$
\frac{\partial S}{\partial t}=\frac{\partial B}{\partial t}-\frac{\operatorname{div} \vec{q}}{\rho_{B}}+b_{S}+b_{B} .
$$

\section{3-D VELOCITY COMPONENTS RELATION}

This section describes an approach for deriving a relation between the vertical surface ice particle (pole) velocity, $w_{S}$, and the two-dimensional horizontal surface velocity, $\vec{v}_{S}$. The first step is to combine the surface boundary condition, (1), and the equation of continuity, (6), which yields

$$
w_{S}=\vec{v}_{S} \cdot \operatorname{grad} S-\frac{\operatorname{div} \vec{q}}{\rho_{B}}+b_{B}+\frac{\partial B}{\partial t} .
$$

This, off course, includes terms describing the processes at the bottom and inside the ice-body. The bottom processes is melt/freeze, described by $b_{B}$, and time-variations of the bottom position, described by $\partial B / \partial t$. For a grounded glacier the bottom terms may often be ignored. For such a glacier the problematic issue is the flux-divergence term, $-\operatorname{div} \vec{q} / \rho_{B}$, which depends on the flow-field and densities inside the glacier.

In order to derive a relation with surface (and bottom) quantities only, the following assumptions are additionally adopted in [3]

ASSUMPTION B: The horizontal velocity in a column may change magnitude but not azimuth. This implies that the horizontal velocity vector at a given depth may be expressed as the surface velocity vector multiplied by a velocity-depth profile.

Assumption C: The velocity-depth profile is constant near the surface and the depth-density profile is constant near the bottom. The two zones with variation does not overlap, see Fig. 2 for an example.

Combined with assumption A, which states time-invariance of the depth-density profile, the following expression for fluxdivergence term was derived in [3]

$$
\frac{\operatorname{div} \vec{q}}{\rho_{B}}=\operatorname{div}\left(\left[\left(\frac{\rho}{\rho_{B}}-1\right)+F\right] h \vec{v}_{S}\right) .
$$

In this equation the vertical variation of the density is accounted for by the mean density in the column, $\rho$. Likewise, the vertical variation of velocity magnitude is accounted for by a velocity profile factor, $F$, which is the ratio between the column mean value and the surface value of $\left|\vec{v}_{S}\right|$.

A further simplification is to assume a slow horizontal variation of $\rho, \rho_{B}$, and $F$. In that case is

$$
\frac{\operatorname{div} \vec{q}}{\rho_{B}} \approx\left[\left(\frac{\rho}{\rho_{B}}-1\right)+F\right] \operatorname{div}\left(h \vec{v}_{S}\right) .
$$




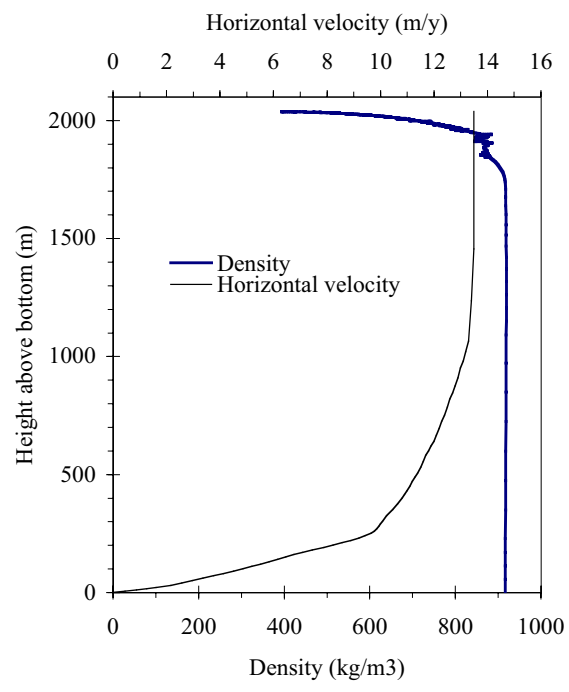

Fig. 2. Density profile (personal communication from S.J. Johnson, 1998) and horizontal velocity profile, [8] from the Dye 3 drilling operations on the South Greenland ice sheet.

\section{ABLATION ZONE APPLICATION}

This section describes simplifications possible in the ablation zone, the resulting relation between the velocity components, and briefly describes an approach for solution of the resulting differential equation(s).

\section{A. Ablation zone simplification}

For a practical application of (7) combined with (8) or (9) the first problem is that the ice-thickness, $h$, has to be known. Today, the most feasible approach is to use airborne ground penetrating radar.

In the ablation zone, $\rho_{S}=\rho_{B}=\rho$. This simplifies the right-hand side of $(8)$, to $\operatorname{div}\left(F h \vec{v}_{S}\right)$. However, without detailed knowledge of the bottom relief and extensive additional modelling the spatial variation of $F$ is difficult to account for. Thus, in our work we use a constant value for $F$, so that (8) is reduced to (9), [4]. Another complication is that the assumption of an flow-direction independent of depth might also be violated near flow around basal obstacles and bumps. We think that $F$ and flow-direction variations are two major, but not prohibitive, error sources.

Finally, values for $b_{B}$ and $\partial B / \partial t$ must be supplied, but most often zeroes would be good estimates.

\section{B. 3-D velocity derivation from interferometry}

Using the above assumptions for a glacier in the ablation zone, the relation between the velocity components becomes

$$
w_{S}=\vec{v}_{S} \cdot \operatorname{grad} S-\operatorname{div}\left(F h \vec{v}_{S}\right) .
$$

Interferometry from ascending and descending orbits provides two measurements of the glacier velocity. The resulting three equations for deriving the 3-D velocity become

$$
\begin{aligned}
& \vec{v} \cdot \hat{n}_{a}=v_{a}, \\
& \vec{v} \cdot \hat{n}_{d}=v_{d}, \\
& \vec{v} \cdot \vec{n}_{s}=-\operatorname{div}\left(F h \vec{v}_{S}\right),
\end{aligned}
$$

where $v_{a}$, and $v_{d}$ are the projections of the unknown glacier velocity $\vec{v}$ on the line-of-sight unit vectors $\hat{n}_{a}, \hat{n}_{d}$ for ascending and descending orbits respectively. The surface normal, $\vec{n}_{s}$, is calculated by $(-\partial S / \partial x,-\partial S / \partial y, 1)$.

With the right-hand side of (11c) set to zero, the above equation system (11) is the well-known system for determining surface parallel flow velocities from interferometry.

It is seen that the use of the equation of continuity just adds an additional term, $-\operatorname{div}\left(F h \vec{v}_{S}\right)$. This term is the submergence/emergence velocity.

\section{Flux-divergence calculation}

The flux-divergence term in (11) prevents a simple pixel by pixel calculation of the 3-D velocities, since one does not have direct access to the spatial derivatives of $F h \vec{v}_{S}$. However, with some averaging of the resulting flux-divergence fields, it is possible to use an iterative approach, [4]. First, the fluxdivergence is set to zero, and the resulting (surface-parallel) velocities are calculated. That flow field is then used to calculate divergences, and the equation system is again solved for the 3 -D velocities. The process is repeated until convergence.

\section{CONCLUSIONS}

In this paper an equation for the submergence/emergence velocity was described. The equation extends the standard surface parallel flow approach with a surface flux-divergence term. The approach to simplification of the underlying mass conservation equations was described and the resulting limitations outlined.

\section{REFERENCES}

[1] I.R. Joughin, R. Kwok, and M.A. Fahnestock, "Interferometric estimation of three-dimensional ice-flow using ascending and descending passes," IEEE Trans. on Geoscience and Remote Sensing, vol. 36, pp. 25-37, 1998.

[2] J.J. Mohr, N. Reeh, and S.N. Madsen, "Three dimensional glacial flow and surface elevation measured with radar interferometry," Nature, vol. 391, pp. 273-276, 1998.

[3] N. Reeh, S.N. Madsen, and J.J. Mohr, "Combining SAR interferometry and the equation of continuity to estimate the three dimensional glacier surface velocity," Journal of Glaciology, vol. 45, no. 151, pp. 533-538, 1999.

[4] N. Reeh, J.J. Mohr, S.N. Madsen, H. Oerter, and N. Gundestrup, “Threedimensional surface velocities of the Storstrømmen glacier derived from radar interferometry and ice-sounding radar measurements," Journal of Glaciology, (submitted, 2000).

[5] J.J. Mohr, N. Reeh, and S.N. Madsen, "Accuracy of three-dimensional glacier surface velocities derived from radar interferometry and icesounding radar measurements," Journal of Glaciology, (submitted, 2001).

[6] W.S.B. Paterson, The Physics of Glaciers, Butterworth-Heinemann, Jordan Hill, Oxford, 3rd edition, 1994.

[7] R.J. Arthern and D.J. Wingham, "The natural fluctuations of firn densification and their effect on the geodetic determination of ice sheet mass balance," Climate Change, vol. 40,pp. 605-624, 1998.

[8] N.S. Gundestrup and B.L. Hansen, "Bore-hole survey at Dye 3, south greenland," Journal of Glaciology, vol. 30, no. 106, pp. 282-288, 1984. 